Holmes, K. R. (1983) Freud, evolution, and the tragedy of man. Journal of the American Psychoanalytical Association, 31, 187210.

Nrrzscke, B. (1983) On the origin of the "id": Freud, Groddeck, Nietzsche-Schopenhauer, E. von Hartmann. Psyche, 37, 769-804.

Strotzkn, H. (1988) Freud und die Philosophie. In Die Philosophen und Freud: eine offene Debatte (eds H. Vetter \& L. Nagh) München: Oldenbourg Verlag.

WaUgaman, R. (1973) The intellectual relationship between Nietzsche and Freud. Psychiatry, 36, 458-467.

A. Karwautz C. WÖBER-BINGÖL C. WÖBER

University of Vienna

Dept. of Neuropsychiatry

of Childhood and Adolescence

1090. Vienna, Austria

\section{Postpartum depression - a specific concept?}

SIR: Cooper \& Murray's conclusions on the specificity of postnatal depression as a diagnostic concept (BJP, February 1995, 166, 191-195) are based on the observation that women who develop postpartum depression without any previous psychiatric history have a better prognosis over a five year period than women with a previous psychiatric history of affective disorder unrelated to childbirth.

This is an important finding as it has been widely held that as the majority of relapses following puerperal illness tend to be non-puerperal in nature, there can be no specificity to the concept of puerperal illness in general and to depression in particular. However, if a puerperal group is divided by past psychiatric history it is quite clearly apparent that the previous history of non-puerperal illness predicts much higher rates of non-puerperal illness later in life. (Dean et al, 1989).

In our study of postpartum admissions to a mother/baby unit (Bell et al, 1994) we found in our follow-up period, which ranged between 5 and 14 years, that only $39 \%$ of the group without any previous psychiatric history to the index admission suffered from subsequent non-puerperal illness compared to $76 \%$ of the women who had previous psychiaric illness prior to their puerperal illness. These are very similar rates to that of the study in question. However, we did not feel able to conclude that this was enough to support the concept of postpartum affective disorder as being a specific entity and I wonder whether the authors could comment on the following points.

Women presenting with postpartum disorder are likely to be young (our group had a mean age of 26 years); therefore, anybody with psychiatric history prior to that point, it could be argued, represents the severer end of a spectrum of psychiatric disorder and therefore is likely to have a worse prognosis.

Also, the young age of the index group is likely to contain some people whose non-puerperal psychiatric disorder had not yet manifested, and this may account for the fact that the majority of recurrences are non-puerperal in nature and that therefore any first episode group is going to be mixed in type.

It might be possible that using previous psychiatric history as a divider could mean selecting out severe from milder forms of affective disorder, and that a short follow up period of five years is not long enough to distinguish them conceptually.

What we had not been able to do, which would be useful, was to look at family histories of affective disorder as well as social and biological variables in these two groups once they had been separated by prognosis and past history.

With all these provisos in mind, there is still a suspicion that postpartum illness does have a better prognosis than would otherwise be expected. In our group, more than half the manics, if they were without previous history to their first episode of postpartum illness, were free of further episodes at eight years, although this group was too small to be statistically significant.

Bell, A. J., Land, N. M., Milne, S., et al (1994) Long-term outcome of postpartum psychiatric illness requiring admission. Journal of Affective Disorders, 3, 67-70.

Dean, C., Williams, R. J. \& Brockington, I. F. (1989) Is puerperal psychosis the same as bipolar manic depressive disorder? A family study. Psychological Medicine, 19, 637-647.

\section{A. J. BeLL \\ N. M. LAND S. MiLNE \\ F. HASSANYEH}

Ashwood MHRC

\section{Guisborough General Hospital}

Cleveland TS14 6HZ

AUTHORS REPLY: The comments of Bell et al arise from a somewhat selective reading of our paper. They focus on the fact that in our study those with postpartum depression in the absence of a previous history of affective disorder were at relatively low risk for subsequent non-puerperal depressive disorder. We agree that an argument for the specificity of the concept of postpartum depression on this basis alone would be difficult to defend. However, when this fact is taken together with the finding that these women were at relatively raised risk for 